\title{
Management of Accommodative Insufficiency with Optometric Vision Therapy: A Case Report
}

\author{
Manish Dahal ${ }^{1}$, Raju Kaiti ${ }^{*}$ and Bishal Hamal ${ }^{1}$ \\ ${ }^{1}$ Consultant Optometrist, B. Optom, Nepal Eye Hospital, Nepal \\ ${ }^{2}$ Consultant Optometrist, M. Optom, Nepal Eye Hospital, Nepal
}

*Corresponding author: Raju Kaiti, M. Optom, Consultant Optometrist, Nepal Eye Hospital, Nepal; Email: rajukaiti@gmail.com

\section{Case Report \\ Volume 5 Issue 1}

Received Date: March 23, 2020

Published Date: June 18, 2020

DOI: 10.23880 /oajo-16000189

\section{Abstract}

Background: Accommodative Insufficiency (AI) is a condition in which a patient has an inability to focus or sustain focus at near. Several management options are available including plus lenses for near and optometric vision therapy.

Case Report: A 14 years old female presented with complaints of headache and blur vision at distance and near, visited optometry clinic. The symptoms were reported as intermittent and associated with reading up close for even short period of time. A comprehensive binocular vision evaluation was performed to determine the presence of any non-strabismic binocular disorder. Accommodative Insufficiency was reported. Optometric vision therapy was recommended with near added lens. Patient reported good compliance and no longer experience blur or headache after long periods of reading using the glasses. Conclusion: Accommodative insufficiency can be successfully managed by optometric vision therapy in adjunction with added plus lens. A detailed binocular and accommodative evaluation is must before prescribing added lens.

Keywords: Accommodative insufficiency; Non-Strabismic Binocular Disorder; Optometric Vision Therapy

\section{Introduction}

Accommodative insufficiency (AI) is a condition that affects the ability to maintain near vision focus for a prolonged time. This is shown clinically by insufficient amplitude of accommodation based on age-expected norms [1]. The American Optometric Association defines accommodative insufficiency as occurring when the amplitude of accommodation is lower than expected for the patient's age and is not due to sclerosis of the crystalline lens [2]. AI has been reported to be a common cause of asthenopia and other symptoms, in schoolchildren, associated with near vision [3].

The inability to concentrate for long periods during near visual work can reduce the level of student achievement, so AI is presented as negative factor in relation to health and quality of life, as it interferes with reading and near work , contribut- ing to diminished performance at school [3-5].

\section{Case Report}

A 14 years old female presented with complaints of headache and blur vision at distance and near visited our clinic. The symptoms were reported as intermittent and associated with reading up close for even short periods of time. Her previous eye exam was 1 year back and she was advised to visit physician to rule out the cause of headache. Eventually, no reasons could be ruled out. There was a normal birth history (full term, normal delivery, birth weight$2.7 \mathrm{~kg}$ ) and normal developmental milestone. Ocular history was normal. On examination her distance visual acuity was 6/6 OD and 6/6 OS. Near vision was N5 on both eyes using Snellen visual acuity chart. Static retinoscopy showed $+0.50 \mathrm{D}$ on both eyes. Cycloplegic retinoscopy was $+1.25 \mathrm{D}$ OD and +1.25 D OS. She was called for a detailed binocular vision 


\section{Open Access Journal of Ophthalmology}

evaluation after 3 days (Table 1).

\begin{tabular}{|c|c|}
\hline Tests & Findings \\
\hline Visual acuity(aided) & OD: 6/6, N6 OS: 6/6, N6 \\
\hline Refractive status & OD: +0.50D \\
\hline Static Retinoscopy & OS: $+0.75 \mathrm{D}$ \\
\hline Wet Retinoscopy (Cyclo) & OD:+1.25D OS:+1.25D \\
\hline Stereopsis(stereofly) & 200 seconds of an arc \\
\hline Cover test & Distance: Orthophoria Near: Esophoria \\
\hline Prism bar cover test & $\begin{array}{c}@ 20 \text { feet: N/A } \\
@ 40 \mathrm{~cm} \text { : 3PD esophoria }\end{array}$ \\
\hline Extraocular motility test & OU: Full range of motion \\
\hline Amplitude of accommodation & $\begin{array}{l}\text { OD: } 7.14 \mathrm{D} \\
\text { OS: } 6.66 \mathrm{D} \\
\text { OU: } 7.14 \mathrm{D}\end{array}$ \\
\hline $\begin{array}{c}\text { Negative Relative } \\
\text { Accommodation(NRA) }\end{array}$ & $+3.00 \mathrm{D}$ \\
\hline Positive Relative Accommodation (PRA) & $-1.00 \mathrm{D}$ \\
\hline $\begin{array}{l}\text { Monocular accommodative } \\
\text { facility(MAF) ( } \pm 2.00 \mathrm{DS})\end{array}$ & OD: $1 \mathrm{cpm}$; difficulty clearing minus OS: $1 \mathrm{cpm}$; difficulty clearing minus \\
\hline $\begin{array}{l}\text { Binocular accommodative Facility(BAF) } \\
( \pm 2.00 \mathrm{DS})\end{array}$ & 2cpm; difficulty clearing minus \\
\hline Monocular estimation method(MEM) & $+2.25 \mathrm{D} \mathrm{OU}$ \\
\hline Near point of convergence(NPC) & $6 \mathrm{~cm}$ \\
\hline Negative fusional vergence(NFV) & @20 feet: ×/8/6@40 cm: ×/15/12 \\
\hline Positive fusional vergence (PFV) & @20 feet: ×/15/12@ @40 cm: 12/16/14 \\
\hline Saccades (NSUCO) & $5 / 5 / 4 / 5$ \\
\hline
\end{tabular}

Table 1: Diagnostic Data from the Initial Evaluation.

$\mathrm{OD}=$ oculus dextrus; $\mathrm{OS}=$ oculus sinister; $\mathrm{NSUCO}=$ Northeastern State University College of Optometry

Upon examination she was diagnosed with

- Moderate Hyperopia

- Accommodative Insufficiency.

\section{Management Plan}

She was prescribed plus lens of $+0.75 \mathrm{D}$ OU at near and suggested to take frequent visual break in between while doing sustained near work and officebased vision therapy was initiated.

\section{Vision Therapy}

Each office therapy session lasted one hour. Monocular accommodative activities OD, OS were started followed by binocular activities. The patient underwent a total of 6 therapy sessions over a period of 15 days. Accommodative assessment was done at the end of therapy sessions. Post-VT, she was advised to continue her glass while doing near work and was called for follow-up after 1 month.

\section{Follow-up}

After one month's follow up visit, the improved accommodative insufficiency and other parameters were well-maintained.

Table 2 shows the diagnostic data from the followup evaluation. Appendix A shows the table of excepted for different tests performed and appendix B shows the sequential vision therapy program. 


\begin{tabular}{|c|c|}
\hline Tests & Follow up evaluation \\
\hline $\begin{array}{l}\text { Visual acuity @ distance } \\
\text { @ near }\end{array}$ & $\begin{array}{l}6 / 6 \\
\mathrm{~N} 6 \\
\end{array}$ \\
\hline Stereopsis(Stereofly) & 25 seconds of arc \\
\hline $\begin{array}{c}\text { Cover test @ distance } \\
\text { @ near }\end{array}$ & Orthophoria 4 exophoria \\
\hline NPC & Till tip of the nose \\
\hline Amplitude of Accommodation & OD:10D OS:10D OU:12.5D \\
\hline MEM & OD:+0.50D OS: +0.50D \\
\hline NRA & $+3.00 \mathrm{D}$ \\
\hline PRA & $-2.50 \mathrm{D}$ \\
\hline Monocular accommodative facility(MAF) $( \pm 2.00 \mathrm{DS})$ & $\begin{array}{l}\text { OD:15CPM(equally clears both plus and minus ) OS: 14CPM ( } \\
\text { equally clears both plus and minus ) }\end{array}$ \\
\hline Binocular accommodative Facility(BAF) $( \pm 2.00 \mathrm{DS})$ & OU: 18CPM (equally clears both plus and minus) \\
\hline Negative fusional vergence(NFV) & @20 feet: ×/10/6@40 cm: ×/22/16 \\
\hline Positive fusional vergence (PFV) & @20 feet: ×/19/12@40 cm: 15/21/14 \\
\hline
\end{tabular}

Table2: Diagnostic Data from the Follow-Up Evaluation

\section{Discussion}

Accommodative insufficiency is one of the common causes of asthenopia and other symptoms associated with near vision [3-5]. This could impact academic performance and ultimately degrades the quality of life. In this case, the patient was 14 years old when we treated her. Therefore, a timely diagnosis can help manage the case of AI successfully with the art of optometric vision therapy.

\section{Conclusion}

Accommodative insufficiency can be successfully managed by optometric vision therapy in adjunction with added plus lens. A detailed binocular and accommodative evaluation is must before initiating therapy and prescribing added lens.

\section{References}

1. Hofstetter HW (1950) Useful age-amplitude formula.
Opt World 38: 42-45.

2. Cooper J (1987) Accommodative dysfunction. In Amos JF (Edn.), Daignosis and management in vision care. Boston: Butterworths 431-459.

3. Borsting E, Rouse MW, Deland PN, Hovett S, Kimura D, et al. (2003) Association of symptoms and convergence and accommodative insufficiency in school-age children. Optometry 74(1): 25-34.

4. Shin HS, Park SC, Park CM (2009) Relationship between accommodative and vergence dysfunctions and academic achievement for primary school children. Ophthalmic Physiol Opt 29(6): 615-624.

5. Scheiman M, Mitchell GL, Cotter S, Rouse M, Borsting E, et al. (2006) Accommodative insufficiency is the primary of symptoms in children diagnosed with convergence insufficiency. Optom Vis Sci 83(11): 857-858. 